\title{
Estimativa da produtividade do milho em função da disponibilidade hídrica em Guarapuava, PR, Brasil ${ }^{1}$
}

\author{
Marcus V. W agner ${ }^{2}$, Sidnei 0 . Jadoski ${ }^{3}$, M arcio F. Maggi ${ }^{4}$, \\ Larissa R. Saito ${ }^{2} \&$ Adenilson dos S. Lima ${ }^{3}$
}

\begin{abstract}
RESU MO
Com este trabalho objetivou-se estimar o potencial médio de produção da cultura do milho em função das variações da disponibilidade hídrica considerando-se a realização da semeadura em diferentes momentos dentro do período recomendado para o município de Guarapuava, Estado do Paraná. Os estudos foram realizados com base na série ininterrupta de dados climáticos do período de 1984 a 2007. A duração do ciclo da cultura foi calculada pelo acúmulo de soma térmica e a disponibilidade de água avaliada pelo balanço hídrico da cultura, ponderando-se a distribuição da precipitação pluvial e a evapotranspiração da cultura. A probabilidade de redução de produtividade de grãos por deficiência hídrica foi estimada considerando-se a porcentagem de redução de produção de grãos a partir da ocorrência de deficiência hídrica nos diferentes estádios do ciclo de desenvolvimento no campo. Verificouse que a cultura do milho é afetada pela distribuição da disponibilidade hídrica ao longo do ciclo, sendo que a maior probabilidade de perdas de produção por deficiência hídrica ocorre no estádio da antesefecundação. As semeaduras mais tardias no período recomendado tendem a ocasionar menores riscos de obtenção de produtividade de grãos abaixo da média regional.
\end{abstract}

Palavras-chave: precipitação pluvial, deficiência hídrica, produção de grãos, Zea mayz L.

\section{Corn yield as a function of water availability in Guarapuava, Paraná, Brazil}

\section{AB STRACT}

This study aimed to estimate the average potential of production of the corn crop in consequence of the variation of the water availability and the planting performed at different dates within the recommended period for Guarapuava, Paraná State, Brazil. The study was conducted considering uninterrupted series of climate data for the period from 1984 to 2007. The duration of the crop cycle was calculated by the accumulation of the thermal sum and the availability of water evaluated by the water balance of the crop considering the distribution of the precipitation and the evapotranspiration of the crop. The probability of reduction of the grain yield due to shortage of water was estimated considering the percentage of the reduction of grain production with the occurrence of water deficiency in the different stages of the crop cycle. It was verified that the corn crop is affected by the distribution of the water availability along the crop cycle, with the highest probability of production losses for water deficiency occurring at the stage of anthesis-fecundation. Late planting in the recommended period tend to cause less risks of having grain productivity below the regional average.

Key words: rainfall, soil water deficit, grain production, Zea mays L.

\footnotetext{
${ }^{1}$ Parte da Dissertação de Mestrado do primeiro autor, apresentada à Universidade Estadual do Centro O este - UN ICENTRO. Guarapuava-PR UNICENTRO. Programa de Pós-graduação em Agronomia. E-mail: mwagner@unicentro.br; Irsaito@unicentro.br

U N ICEN TRO. Departamento de Agronomia. Av. Simeão Camargo V. de Sá, CEP 85040-080, Guarapuava, PR. Fone: (42) 3629-8213. E-mail: sjadoski@unicentro.br; aslima@unicentro.br

${ }^{4}$ U N IO ESTE. Programa de Pós-G raduação em Engenharia de Sistemas Agroindustriais. CEP 85819-110, Cascavel, PR. Fone: (45) 3220-3199. E-mail: mmaggi@unioeste.br
} 


\section{INTRODUÇÃO}

O desenvolvimento adequado das culturas agrícolas é dependente dos fatores referentes à dinâmica do sistema soloplanta-atmosfera, como disponibilidade de água no solo, evapotranspiração e aproveitamento da água pelas plantas. Castellví et al. (2004) descrevem que a deficiência hídrica do solo é condicionada pela relação entre a precipitação e a evapotranspiração e por sua capacidade de água disponível, que é variável entre diferentes locais podendo ser modificada pelo manejo adotado. Contudo, supõe-se que o comportamento da disponibilidade de água às plantas apresente semelhança com a distribuição dos índices de precipitação.

Em relação aos efeitos do clima, Nied et al. (2005) apresentam resultados de diferentes pesquisas demonstrando que a precipitação pluvial é a principal variável climática que, ao longo dos anos, tem determinado as variações na produção de grãos da maioria das culturas na região Sul do Brasil. Para a cultura do milho Fiorin et al. (2009) salientam que a importância dos fatores que afetam o desenvolvimento da cultura varia conforme a região do país. Observa-se que, em geral, o milho tem sido plantado principalmente no período chuvoso visando à disponibilidade de água para cultura sem necessidade de irrigação.

O conhecimento sobre distribuição e volume das precipitações pluviais é fundamental para o planejamento das atividades agrícolas, como definição das datas mais apropriadas para semeadura, tratos culturais e manejo de sistemas de irrigação visando evitar o estresse hídrico nas plantas (Klar et al., 2006). Costa et al. (2008) observaram que a cultura do milho é afetada de diferentes formas, pela deficiência hídrica, com alterações no crescimento das plantas e expansão da área foliar durante os estádios vegetativos e da produção de matéria seca da parte aérea, quando ocorreu disponibilidade hídrica insuficiente nos estádios reprodutivos do ciclo da cultura.

Nas diferentes regiões a disponibilidade hídrica é um dos principais fatores considerados na definição dos períodos preferenciais de cultivo para obtenção das melhores produtividades. Em referência ao zoneamento agrícola e às suas aplicações, Dallacort et al. (2006) sugerem, para fins de estimativa da produtividade de cultivos, que os modelos matemáticos baseados em princípios agroclimatológicos mais importantes, são aqueles que simulam as fases de desenvolvimento e de maturação das culturas, a disponibilidade de umidade no solo e os efeitos do estresse hídrico no rendimento. Para os autores, os modelos são dinâmicos e funcionais haja vista que descrevem mudanças diárias nas variáveis da cultura, considerando os principais processos morfofisiológicos que nela ocorrem.

Desta forma, o objetivo da pesquisa foi estimar o potencial médio de produção da cultura do milho em função das variações da disponibilidade hídrica nos diferentes estádios do ciclo de desenvolvimento das plantas, considerando-se a semeadura em diferentes datas dentro do período recomendado para Guarapuava, conforme o zoneamento agrícola do estado do Paraná.

\section{MATERIAL E MÉTODOS}

O estudo foi desenvolvido tendo-se, como base, uma série histórica de dados climatológicos médios diários de temperatura, umidade relativa do ar, precipitação pluvial, radiação solar e velocidade do vento, para o período de 1984 a 2007. Os dados foram compilados do acervo da estação meteorológica da Universidade Estadual do Centro Oeste UNICENTRO, em Guarapuava, PR (latitude 2523' 02" S, longitude 51 29' 43" W a 1026 m de altitude).

Os tratamentos constaram da simulação de diferentes datas de semeadura da cultura considerando-se o zoneamento agrícola do Estado do Paraná apresentado por Caramori (2003), que define o período de 21 de setembro a 10 de novembro como recomendado para a semeadura; assim, foram definidos os seguintes tratamentos: T1) 21 de setembro, T2) 01 de outubro, T3) 11 de outubro, T4) 21 de outubro, T5) 31 de outubro e T6) 10 de novembro, a partir das quais foi avaliada a probabilidade de ocorrência de deficiência hídrica e suas consequências sobre a produtividade estimada da cultura.

O ciclo vegetativo das plantas foi subdividido em diferentes estádios fenológicos segundo Ritchie et al. (1993) e adaptação apresentada por Fancelli \& Dourado Neto (1997), sendo: 1) VE-V6 - Emergência à sexta folha; 2) V7-V10 - Sétima à décima folha; 3) V10-VT - Décima folha ao pendoamento; 4) VT Pendoamento; 5) A-F(R1) - Antese-Florescimento (fecundação); 6) R2 - Grão leitoso; 7) R3 - Grão pastoso; 8) R4 - MF Grão farináceo-Maturidade fisiológica. Conforme Ritchie et al. (1993) os estádios "antese (A) - florescimento e fecundação (R1)" apresentam curta duração temporal e relações fisiológicas aproximadamente similares quanto à água disponível no solo os quais foram, desta forma, considerados em conjunto para as avaliações, como sendo A-F(R1).

As avaliações foram realizadas com base no comportamento normal de uma cultivar hipotética de milho com características do grupo precoce, por ser a mais cultivada na região, conforme SEAB-DERAL (2007).

Utilizou-se a exigência em soma térmica para delimitação dos estádios fenológicos e duração do ciclo da cultura considerando-se o acúmulo de unidades térmicas diárias (UTD) tendo-se, como referência, resultados de diferentes pesquisas mostradas em Gadioli et al. (2000) e Nied et al. (2005) na Tabela 1. Para totalizar a duração do ciclo de desenvolvimento até a

Tabela 1. U nidades térmicas diárias (UTD ) necessárias para completar os diferentes estádios do ciclo de desenvolvimento fenológico da cultura do milho precoce

\begin{tabular}{cc}
\hline Fases fenológicas $^{*}$ & UTD acumuladas \\
VE-V6 & $0-295$ \\
V7- V10 & $295-470$ \\
V10-VT & $470-660$ \\
VT & $660-857$ \\
A-F(R1) & $857-1010$ \\
R2 & $1010-1130$ \\
R3 & $1130-1320$ \\
R4-MF & $1320-1690$ \\
\hline
\end{tabular}

* VE-V6 - Emergência à sexta folha; V7-V10 - Sétima à décima folha; V10-VT - Décima folha ao pendoamento; VT - Pendoamento; A-F(R1) - Antese-Florescimento (fecundação); R2 - Grão leitoso; R3 - Grão pastoso; R4 - MF Grão farináceo-Maturidade fisiológica 
maturação fisiológica foi adicionado o período de seis dias, tempo necessário para a germinação e emergência das plantas, conforme observado por Constantin et al. (2007).

A soma térmica foi contabilizada a partir das unidades térmicas diárias (UTD) acumuladas e que foram determinadas considerando-se as temperaturas diárias limitadas aos extremos de 32 e $10{ }^{\circ} \mathrm{C}$, como temperatura base superior e inferior, respectivamente, conforme Monteith \& Elston (1996).

A disponibilidade hídrica para a cultura foi determinada para o período de 1984 a 2007 com base nos resultados do cálculo do balanço hídrico de Thornthwaite-Mather conforme metodologia descrita por Pereira (2005). A partir da estimativa da duração dos estádios fenológicos realizou-se avaliação da distribuição média da precipitação pluvial com a totalização para os diferentes estádios e para o ciclo completo da cultura nas diferentes datas de semeaduras consideradas.

A evapotranspiração de referência (ETo) foi estimada pelo método de Penman-Monteith, modelo padrão FAO (Allen et al., 1998). A evapotranspiração máxima da cultura (ETmc) foi determinada com a expressão: ETmc $=$ ETo x Kc, utilizando-se os coeficientes de cultura $(\mathrm{Kc})$ conforme adaptação de Doorenbos \& Kassam (1979), e apresentados na Tabela 2.

Tabela 2. Coeficiente de cultura $(\mathrm{Kc})$ para os estádios do ciclo de desenvolvimento fenológico do milho

\begin{tabular}{cc}
\hline Estádios fenológicos $^{*}$ & Kc \\
VE - V6 & $0,3-0,5$ \\
V7 - V10 & 0,7 \\
V10 - VT & 0,8 \\
VT & 1,0 \\
A-F(R1) & 1,1 \\
R2 & 1,0 \\
R3 & $0,9-0,8$ \\
R4 & $0,65-0,55$ \\
\hline
\end{tabular}

* VE-V6 - Emergência à sexta folha; V7-V10 - Sétima à décima folha; V10-VT - Décima folha ao pendoamento; VT - Pendoamento; A-F(R1) - Antese-Florescimento (fecundação); R2 - Grão leitoso; R3 - Grão pastoso; R4 - MF Grão farináceo-Maturidade fisiológica

Para as estimativas a ETmc acumulada foi subdividida em intervalos (Tabela 3) definidos a partir de adaptações considerando-se resultados de pesquisa de Camp \& Campbell (1998) e Carlesso et al. (2000) obtidos em condições climáticas similares às dos experimentos, sendo: 1) "lâmina ótima", em que a cultura apresenta máximo desenvolvimento e capacidade produtiva; 2) "lâmina deficiente" o limite de ETmc acumulada até $50 \%$ superior à lâmina ótima; nessas condições ocorrem perdas crescentes do potencial produtivo, em função do aumento da deficiência hídrica; 3) "lâmina crítica" cuja ETmc acumulada é superior à lâmina deficiente.

Tabela 3. Classificação das lâminas de evapotranspiração máxima da cultura, de acordo com ciclo de desenvolvimento fenológico do milho

\begin{tabular}{ccc}
\hline \multirow{2}{*}{ Intervalo } & \multicolumn{2}{c}{ Estádios fenológicos $^{*}$} \\
\cline { 2 - 3 } & VE a V6 $(\mathbf{m m})$ & V7 a $\mathbf{R 3}(\mathbf{m m})$ \\
Lâmina ótima & $0-18$ & $0-32$ \\
Lâmina deficiente & $18-27$ & $32-48$ \\
Lâmina crítica & $>27$ & $>48$ \\
\hline *VE a V6 - emergência a sexta folha; V7 a R3 - sétima folha a grão pastoso
\end{tabular}

As diferenças entre VE a V6 e V7 a R3, foram estabelecidas devido ao desenvolvimento inicial da cultura com menor capacidade de exploração pelo sistema radicular no primeiro estádio e ao fato de que, após o R3, a cultura entra em maturação fisiológica, com respostas pouco significativas à disponibilidade de água no solo.

Os impactos da deficiência hídrica sobre a perda de produtividade foram determinados com base nas informações de Claassen \& Shaw (1970) e Tacker et al. (2003), e nos seguintes critérios: a) zero na lâmina ótima; b) com variação progressiva de 0 a 100\% nos limites mínimos e máximos da lâmina deficiente, em que o valor zero significa a não ocorrência de deficiência hídrica e o valor $100 \%$ indica a ocorrência do máximo efeito de redução de produção atribuído ao déficit hídrico no referido estádio fenológico; c) os valores de ETmc acumulada que atingem o intervalo correspondente à lâmina crítica, embora considerados para o balanço hídrico, não ocasionam efeito aditivo na redução da produtividade estimada além do valor máximo de $100 \%$ relativo à lâmina deficiente (Tabela 4).

Tabela 4. Porcentagem de redução de produção de grãos pela ocorrência de deficiência hídrica nos diferentes estádios ciclo de desenvolvimento fenológico da cultura do milho

\begin{tabular}{cc}
\hline Estádio fenológico & Redução da produção de grãos (\%) \\
VE - V6 & 5 \\
V7 - V10 & 5 \\
V10 - VT & 10 \\
VT & 15 \\
A-F(R1) & 35 \\
R2 & 10 \\
R3 & 5 \\
\hline
\end{tabular}

* VE-V6 - Emergência à sexta folha; V7-V10 - Sétima à décima folha; V10-VT - Décima folha ao pendoamento; VT - Pendoamento; A-F(R1) - Antese-Florescimento (fecundação); R2 - Grão leitoso; R3 - Grão pastoso

Para estimar o efeito proporcional de deficiência hídrica que determinada ETmc acumulada pode ocasionar sobre a produtividade (Tabela 4) e estabelecer parâmetros para a classificação da intensidade de deficiência hídrica em função da data de semeadura, o intervalo da lâmina deficiente (18 a 27 mm para VE-V6 e 32 a $48 \mathrm{~mm}$ a partir de V7) foi dividido em quatro subintervalos os quais foram correlacionados aos quartis de porcentagem de: 1) 18 a 20,25 mm =1-25\%; 2) 20,26 a $22,5 \mathrm{~mm}=26-50 \%$; 3) 22,6 a 24,75 $\mathrm{mm}=51-75 \%$ e 4) 24,76 a e" $27 \mathrm{~mm}=76-100 \%$ para VE-V6 e a partir de V7 1) 32 a $35,9 \mathrm{~mm}=$ $1-25 \%$;2) 36,0 a $39,9 \mathrm{~mm}=26-50 \%$; 3) 40,0 a $43,9 \mathrm{~mm}=51-75 \%$ e 4) 44,0 a e" $50,0 \mathrm{~mm}=76-100 \%$.

As estimativas foram realizadas considerando-se o teto de produtividade de $14.000 \mathrm{~kg} \mathrm{ha}^{-1}$ na região de Guarapuava, PR, a ser alcançado sem ocorrência de deficiência hídrica, em lavouras conduzidas com padrões de fertilidade do solo, manejo cultural e sanidade adequada para a cultura, conforme relata SEAB-DERAL (2007).

Para as estimativas de armazenamento da água no solo foram ponderados valores médios para os solos predominantes nas lavouras da região classificados, de acordo com EMBRAPA (2006) "Latossolo Bruno Álico distroférrico" tendo, em média, densidade de $1,25 \mathrm{~g} \mathrm{~cm}^{-3}$ e $50 \%$ de porosidade total distribuídos em $12 \%$ de macroporos e $38 \%$ de microporos. 
Conforme metodologia adaptada de Espinoza (1980) também se definiu, a partir de estudo desenvolvido em Latossolo, a profundidade de $0,50 \mathrm{~m}$ para zona de extração de água pelo sistema radicular da cultura do milho e a lâmina correspondente a $80 \%$ do total de capacidade de armazenamento de água no solo como fração máxima possível de ser retirada por evapotranspiração. Desta forma, a lâmina total estimada de armazenamento na profundidade de $0,50 \mathrm{~m}$ é de $237,5 \mathrm{~mm}$ e a lâmina total extraível por evapotranspiração no local é de $190 \mathrm{~mm}$.

Para a análise estatística as médias foram submetidas a teste de normalidade e realizada análise de variância cujos fatores qualitativos foram, posteriormente, submetidos ao teste de comparação de médias pelo método de Tukey com nível de significância de 95\% e, quando necessário, estabelecidas linhas de tendência por análise de regressão para dados quantitativos utilizando-se o software estatístico Assistat, versão 7.5 beta. As análises descritivas foram realizadas pelo agrupamento em Quartis de porcentagem considerando-se definições matemáticas para frequência relativa, conforme Cargnelutti Filho et al. (2004).

\section{RESULTADOS E DISCUSSÃO}

Os resultados da avaliação da duração dos estádios fenológicos e do ciclo vegetativo total da cultura do milho, determinados a partir da soma térmica derivada de valores médios climáticos de 24 anos, são apresentados na Tabela 5.
Verifica-se que o ciclo vegetativo total estimado varia entre 114 e 122 dias, com sequencial encurtamento para semeaduras mais tardias em relação ao início do período recomendado a partir de 21 de setembro. Este encurtamento do ciclo entre as datas extremas de semeadura foi de aproximadamente oito dias. Esta diferença, embora expressiva, pode ser maior em regiões com características climáticas diferentes, conforme se verifica em Gadioli et al. (2000) e Forsthofer et al. (2004) que observaram claros efeitos das características ambientais em relação à soma térmica, na duração do ciclo da cultura do milho.

Ao se analisar a duração total das fases fenológicas do período vegetativo (VE a VT) na Tabela 5, verificam-se valores entre 60 e 53 dias para as semeaduras realizadas em 21 de setembro e 10 de novembro, respectivamente. Observa-se, conforme as datas de semeaduras avançaram no tempo, que ocorreu redução do tempo necessário para serem completados os estádios fenológicos vegetativos, o que se deve ao acúmulo mais acelerado de soma térmica em conformidade com o aumento das temperaturas na região. Esses resultados representam as principais diferenças na duração do ciclo vegetativo total já que, na fase reprodutiva, as diferenças são pouco expressivas; já para o período reprodutivo as plantas semeadas em 21 de setembro chegarão à antese aproximadamente em 30 de novembro (70 dias após a semeadura) caso em que, independente da data de semeadura, a duração dos estádios da fase reprodutiva tenderá a estabilizar devido à redução da taxa de aumento da temperatura. Este comportamento é determinado pelas condições climáticas da região Sul onde

Tabela 5. Duração média, em dias, dos estádios ciclo de desenvolvimento fenológico da cultura do milho determinados com base na soma térmica

\begin{tabular}{|c|c|c|c|c|c|c|c|c|c|}
\hline \multirow{2}{*}{$\begin{array}{c}\text { Datas de } \\
\text { semeadura }\end{array}$} & \multicolumn{8}{|c|}{ Duração dos estádios fenológicos* (dias) } & \multirow{2}{*}{$\begin{array}{l}\text { Ciclo vegetativo } \\
\text { total (dias) }\end{array}$} \\
\hline & VE-V6 & V7 & V10 & VT & A-F(R1) & R2 & R3 & R4-MF & \\
\hline 21 set & $22,33 a$ & $12,66 \mathrm{a}$ & $12,95 \mathrm{a}$ & $12,70 \mathrm{a}$ & $9,50 a$ & $7,37 \mathrm{a}$ & $11,70 \mathrm{a}$ & $22,45 a b$ & $121,91 \mathrm{a}$ \\
\hline 01 out & $21,33 b$ & $12,08 \mathrm{ab}$ & $12,08 \mathrm{~b}$ & $12,37 \mathrm{ab}$ & $9,70 \mathrm{a}$ & $7,41 \mathrm{a}$ & $11,37 a$ & $22,45 a b$ & $119,50 \mathrm{~b}$ \\
\hline 11 out & 20,66 bc & $11,95 a b c$ & $12,33 a b$ & $12,16 a b$ & $9,75 \mathrm{a}$ & $7,16 \mathrm{a}$ & $11,16 \mathrm{a}$ & $22,50 a b$ & $117,50 \mathrm{c}$ \\
\hline 21 out & $20,04 \mathrm{~cd}$ & 11,66 bc & $11,70 \mathrm{~b}$ & $12,29 a b$ & $9,58 \mathrm{a}$ & $7,08 \mathrm{a}$ & $11,08 \mathrm{a}$ & $22,41 \mathrm{~b}$ & $115,87 d$ \\
\hline 31 out & $19,37 \mathrm{de}$ & $11,33 b c$ & $11,79 b$ & $11,95 b$ & $9,29 a$ & $7,04 \mathrm{a}$ & $11,33 \mathrm{a}$ & $22,58 \mathrm{ab}$ & $114,70 \mathrm{e}$ \\
\hline 10 nov & $18,87 \mathrm{e}$ & $11,16 \mathrm{c}$ & $11,58 \mathrm{~b}$ & $11,70 \mathrm{~b}$ & $9,25 a$ & $7,04 \mathrm{a}$ & 11,04 a & 23,16 a & $113,83 \mathrm{e}$ \\
\hline Média & 20,43 & 11,81 & 12,07 & 12,20 & 9,54 & 7,18 & 11,28 & 22,59 & 117,25 \\
\hline DMS & 0,97 & 0,85 & 0,79 & 0,73 & 0,52 & 0,57 & 0,68 & 0,74 & 0,94 \\
\hline
\end{tabular}

* VE-V6 - Emergência à s exta folha; V7 - Sétima folha; V10 - Décima folha; VT - Pendoamento; A-F(R1) - Antese-Florescimento (fecundação); R2 - Grão leitoso; R3 - Grão pastoso; R4 - MF Grão farináceo-Maturidade fisiológica

Na coluna, médias seguidas da mesma letra não diferem estatisticamente entre si pelo Teste de Tukey $(p<0,05)$

Tabela 6. Precipitação pluvial durante o ciclo de desenvolvimento da cultura do milho com base em dados climáticos de 1984 a 2007

\begin{tabular}{|c|c|c|c|c|c|c|c|c|c|}
\hline \multirow{2}{*}{ Semeadura } & \multicolumn{8}{|c|}{ Estádios fenológicos* } & \multirow{2}{*}{$\begin{array}{c}\text { Total no } \\
\text { ciclo }\end{array}$} \\
\hline & VE-V6 & V7-V10 & V10-VT & VT & $A-F(R 1)$ & R2 & R3 & R4 MF & \\
\hline \multicolumn{10}{|c|}{ Precipitação pluvial (mm) } \\
\hline 21-set & $161,37 \mathrm{a}$ & $74,00 \mathrm{a}$ & $65,15 a$ & $77,38 \mathrm{a}$ & 49,71 a & $58,91 \mathrm{~A}$ & $65,35 a$ & $145,70 \mathrm{a}$ & 697,66 a \\
\hline 01-out & $140,94 a b$ & 66,62 a & $66,80 \mathrm{a}$ & 65,07 a & 63,50 a & $37,18 \mathrm{~A}$ & $65,06 a$ & $147,80 \mathrm{a}$ & $653,54 a b$ \\
\hline 11-out & $123,09 a b c$ & 64,09 a & $58,10 a$ & $72,66 \mathrm{a}$ & $53,45 a$ & $43,48 \mathrm{~A}$ & $58,04 a$ & 159,72 a & $632,66 \mathrm{~b}$ \\
\hline 21-out & $113,71 a b c$ & $53,92 \mathrm{a}$ & $66,37 a$ & 74,18 a & $56,25 a$ & $35,28 a$ & $87,67 \mathrm{a}$ & $143,08 \mathrm{a}$ & $630,49 \mathrm{~b}$ \\
\hline 31-out & 93,72 bc & 65,06 a & 67,84 a & $71,55 a$ & $46,68 \mathrm{a}$ & $60,90 \mathrm{a}$ & $70,52 \mathrm{a}$ & $152,48 \mathrm{a}$ & $628,78 \mathrm{~b}$ \\
\hline 10-nov & $86,43 c$ & 73,68 a & $56,73 a$ & $62,70 \mathrm{a}$ & $78,47 a$ & $44,65 a$ & 78,28 a & 137,68 a & $620,66 \mathrm{~b}$ \\
\hline DMS & 49,82 & 33,21 & 33,12 & 39,36 & 36,36 & 31,88 & 36,89 & 45,03 & 61,53 \\
\hline
\end{tabular}

* VE-V6 - Emergência à sexta folha; V7-V10 - Sétima à décima folha; V10-VT - Décima folha ao pendoamento; VT - Pendoamento;A-F(R1) - Antese-Florescimento (fecundação); R2 - Grão leitoso; R3 - Grão pastoso; R4 - MF Grão farináceo-Maturidade fisiológica

Na coluna, médias seguidas pela mesma letra não diferem estatisticamente entre si pelo Teste de Tukey $(p<0,05)$ 
predominam os climas subtropical e temperado (Villa-Nova \& Pereira, 2006). Os resultados estão de acordo com Bergamaschi et al. (2006) que observaram redução na duração dos estádios vegetativos do milho quando o incremento da soma térmica ocorreu mais rapidamente.

A lâmina total de precipitação pluvial e sua distribuição nos estádios de desenvolvimento da cultura são apresentadas na
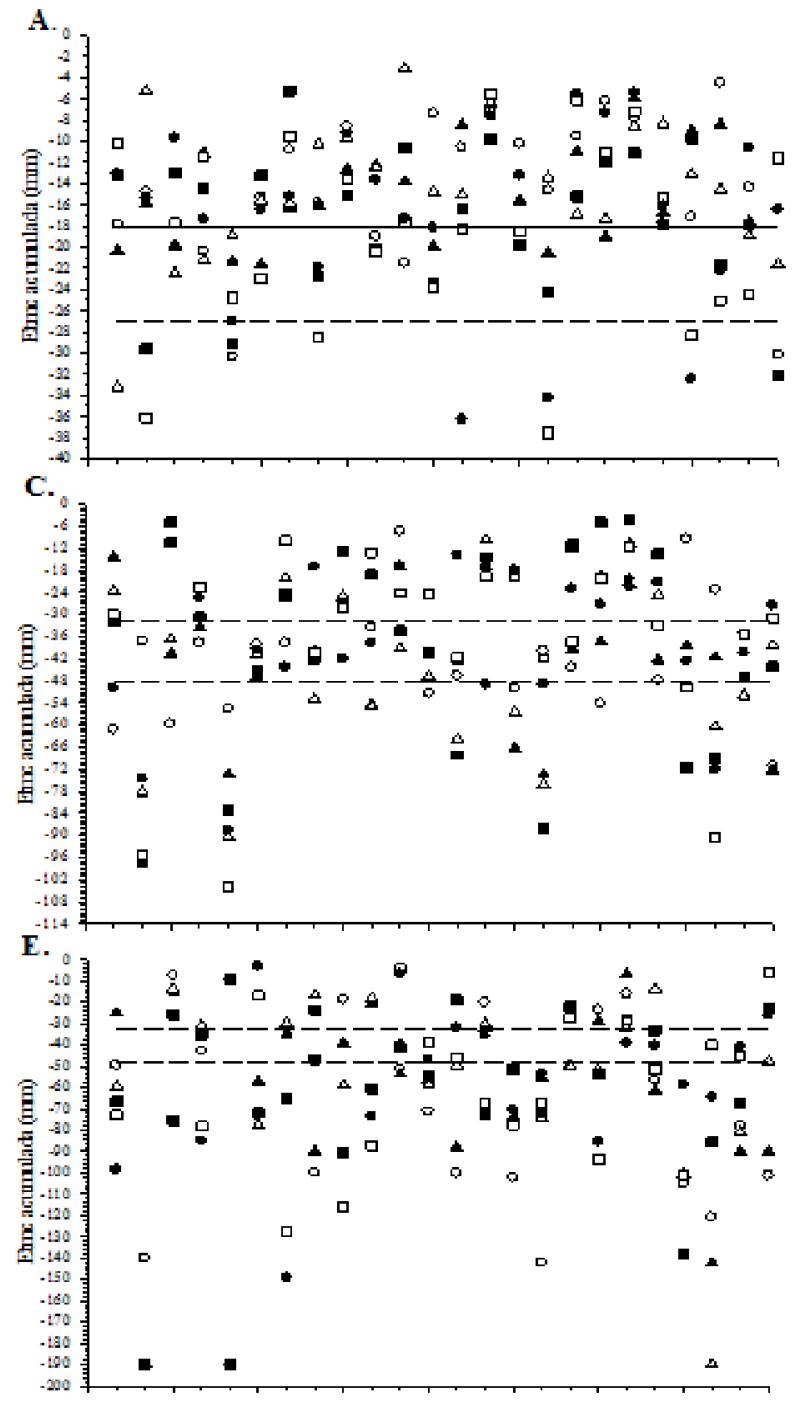

G

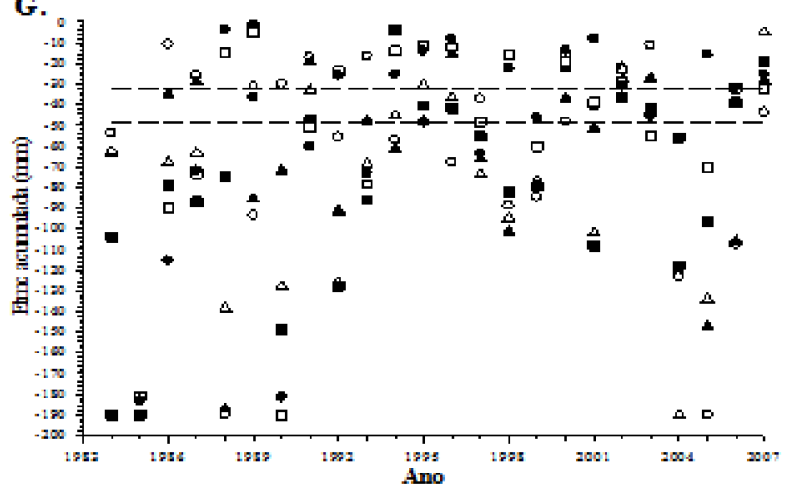

Tabela 6. São observadas diferenças nas lâminas de precipitação somente no estádio VE-V6 cujos índices para a semeadura em 21 de setembro e 01 de outubro tendem a ser superiores em relação a 31 de outubro e 10 de novembro. Tais resultados se devem às diferenças nos índices de precipitação ao longo tempo e à variabilidade da duração de estádios fenológicos inerentes às diferentes datas de semeadura (Tabela 5).
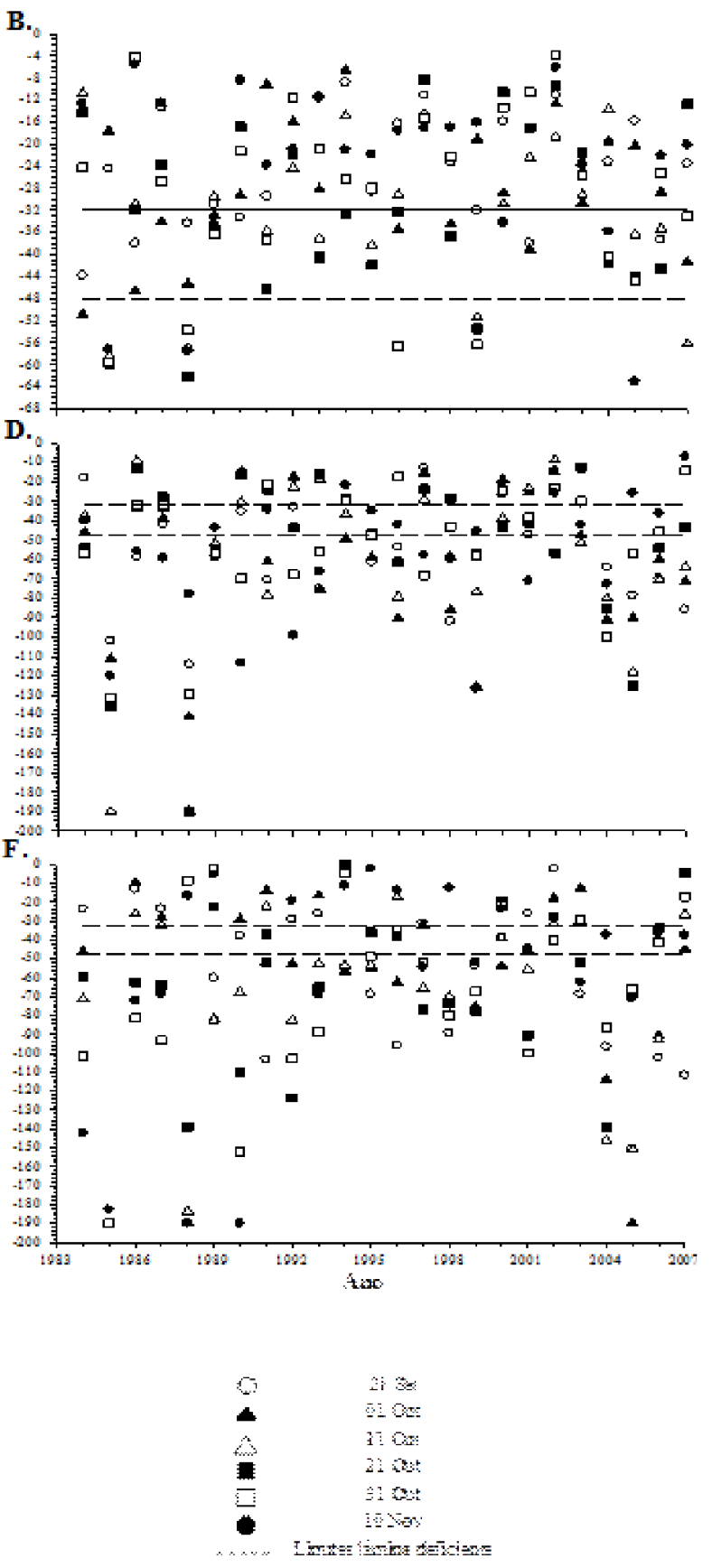

Figura 1. Evapotranspiração máxima acumulada da cultura nos estádios fenológicos A. VE-V6 (Emergência à sexta folha), B. V7-V10 (Sétima à décima folha), C. V10-VT (Décima folha ao pendoamento), D. VT (Pendoamento), E. A-F(R1) (Antese-Florescimento (fecundação)), F. R2 (G rão leitoso) e G. R3 (G rão pastoso), do ciclo de desenvolvimento do milho em diferentes épocas de semeadura, com base em dados climáticos de 1984 a 2007 
A estimativa da evapotranspiração máxima da cultura (ETmc) acumulada para os diferentes estádios fenológicos do milho é apresentada na Tabela 7. A ETmc acumulada para o ciclo da cultura apresenta redução, conforme as semeaduras vão sendo realizadas mais tardiamente dentro do período recomendado. A diminuição de $397,8 \mathrm{~mm}$ para 368,4 mm na demanda hídrica total estimada para o ciclo entre as datas extremas de semeadura representa aproximadamente $8 \%$ da ETmc acumulada total (Tabela 7) fato associado à menor duração do ciclo total para a semeadura mais tardia (Tabela 5).

Na Figura 1 é apresentada a avaliação do balanço hídrico sequencial de 1984 a 2007 buscando-se identificar a ocorrência de deficiência hídrica através de períodos nos quais a ETmc acumulada atinja valores fora dos limites ótimos para os

Tabela 7. Evapotranspiração máxima da cultura (ETMc) acumulada durante o ciclo de desenvolvimento da cultura do milho, determinada com base em dados climáticos de 1984 a 2007

\begin{tabular}{|c|c|c|c|c|c|c|c|c|c|}
\hline \multirow{2}{*}{$\begin{array}{c}\text { Data de } \\
\text { semeadura }\end{array}$} & \multicolumn{8}{|c|}{ Estádios fenológicos ${ }^{*}$} & \multirow{2}{*}{$\begin{array}{c}\text { Total no } \\
\text { ciclo }\end{array}$} \\
\hline & VE-V6 & V7-V10 & V10-VT & VT & $A-F(R 1)$ & R2 & R3 & R4 - MF & \\
\hline \multicolumn{10}{|c|}{$\mathrm{ETmc}(\mathrm{mm})$} \\
\hline 21-set & $35,50 a$ & $39,45 a$ & $50,04 a b$ & $65,45 b$ & $56,29 b$ & $35,95 \mathrm{a}$ & $50,17 \mathrm{~b}$ & $65,07 \mathrm{~A}$ & $397,84 a$ \\
\hline 01-out & $35,91 \mathrm{ab}$ & $39,20 a$ & $52,58 \mathrm{~b}$ & $63,91 a b$ & $53,17 a b$ & $36,45 a$ & $47,87 \mathrm{~b}$ & $66,01 \mathrm{~A}$ & $395,21 \mathrm{a}$ \\
\hline 11-out & $36,16 a b$ & $41,87 a$ & $51,08 a b$ & $61,66 a b$ & $54,10 a b$ & $34,54 \mathrm{a}$ & $47,83 \mathrm{~b}$ & $63,35 \mathrm{~A}$ & $390,39 a b$ \\
\hline 21-out & $38,08 a b$ & $41,62 a$ & $48,87 a b$ & $62,16 a b$ & $49,95 a b$ & $35,12 \mathrm{a}$ & $45,70 a b$ & $62,92 \mathrm{~A}$ & 384,38 bc \\
\hline 01-nov & $38,79 a b$ & $41,58 \mathrm{a}$ & $46,70 \mathrm{a}$ & $58,79 a b$ & $51,00 a b$ & $32,54 a$ & $46,33 a b$ & $62,04 \mathrm{~A}$ & $377,59 \mathrm{c}$ \\
\hline 11-nov & $39,20 \mathrm{~b}$ & $37,41 \mathrm{a}$ & $47,50 a b$ & 57,16 a & $48,54 \mathrm{a}$ & 33,91 a & $41,79 a$ & $63,06 \mathrm{~A}$ & $368,39 d$ \\
\hline DMS & 3,59 & 5,26 & 5,77 & 7,32 & 6,94 & 5,43 & 5,65 & 6,06 & 7,97 \\
\hline
\end{tabular}

* VE-V6 - Emergência à sexta folha; V7-V10 - Sétima à décima folha; V10-VT - Décima folha ao pendoamento; VT - Pendoamento; A-F(R1) - Antese-Florescimento (fecundação); R2 - Grão leitoso; R3 - Grão pastoso; R4 - MF Grão farináceo-Maturidade fisiológica

Na coluna, médias seguidas da mesma letra não diferem estatisticamente entre si pelo Teste de Tukey $(p<0,05)$

Tabela 8. Probabilidade de ocorrência de lâminas de evapotranspiração máxima acumulada da cultura (ETmc) nos estádios fenológicos do ciclo de desenvolvimento do milho em diferentes épocas de semeadura, com base em dados climáticos de 1984 a 2007

\begin{tabular}{|c|c|c|c|c|c|c|c|c|}
\hline \multirow{2}{*}{ Intervalo } & VE - V6 & V7 & $\mathrm{V} 10$ & VT & $A-F(R 1)$ & R2 & R3 & \multirow{2}{*}{$\begin{array}{c}\text { Total ciclo } \\
(\%)\end{array}$} \\
\hline & \multicolumn{7}{|c|}{ \% da ETmc acumulada } & \\
\hline & \multicolumn{8}{|c|}{ Semeadura de 21 de setembro } \\
\hline Lâmina ótima & 79,17 & 75,00 & 25,00 & 25,00 & 29,17 & 33,33 & 29,17 & 42,26 \\
\hline Lâmina deficiente & 16,67 & 29,17 & 45,83 & 12,50 & 4,17 & 8,33 & 12,50 & 18,45 \\
\hline Lâmina crítica & 8,33 & 0,00 & 29,17 & 58,33 & 62,50 & 58,33 & 58,33 & 39,28 \\
\hline \multirow[t]{2}{*}{ Total (\%) } & 100 & 100 & 100 & 100 & 100 & 100 & 100 & 100 \\
\hline & \multicolumn{8}{|c|}{ Semeadura de 01 de outubro } \\
\hline Lâmina ótima & 70,83 & 62,50 & 25,00 & 25,00 & 33,33 & 33,33 & 29,17 & 39,88 \\
\hline Lâmina deficiente & 29,17 & 33,33 & 29,17 & 16,67 & 16,67 & 16,67 & 20,83 & 23,21 \\
\hline Lâmina crítica & 0,00 & 4,17 & 45,83 & 58,33 & 50,00 & 50,00 & 50,00 & 36,90 \\
\hline \multirow[t]{2}{*}{ Total $(\%)$} & 100 & 100 & 100 & 100 & 100 & 100 & 100 & 100 \\
\hline & \multicolumn{8}{|c|}{ Semeadura de 11 de outubro } \\
\hline Lâmina ótima & 75,00 & 58,33 & 37,50 & 29,17 & 33,33 & 29,17 & 29,17 & 41,67 \\
\hline Lâmina deficiente & 20,83 & 25,00 & 25,00 & 25,00 & 12,50 & 4,17 & 12,50 & 17,86 \\
\hline Lâmina crítica & 4,17 & 16,67 & 37,50 & 45,83 & 54,17 & 66,67 & 58,33 & 40,48 \\
\hline \multirow[t]{2}{*}{ Total (\%) } & 100 & 100 & 100 & 100 & 100 & 100 & 100 & 100 \\
\hline & \multicolumn{8}{|c|}{ Semeadura de 21 de outubro } \\
\hline Lâmina ótima & 66,67 & 54,17 & 41,67 & 41,67 & 25,00 & 20,83 & 16,67 & 38,10 \\
\hline Lâmina deficiente & 20,83 & 25,00 & 25,00 & 16,67 & 12,50 & 20,83 & 25,00 & 20,83 \\
\hline Lâmina crítica & 12,50 & 20,83 & 33,33 & 41,67 & 62,50 & 58,33 & 58,33 & 41,07 \\
\hline \multirow[t]{2}{*}{ Total $(\%)$} & 100 & 100 & 100 & 100 & 100 & 100 & 100 & 100 \\
\hline & \multicolumn{8}{|c|}{ Semeadura de 31 de outubro } \\
\hline Lâmina ótima & 58,33 & 62,50 & 58,33 & 37,50 & 29,17 & 25,00 & 41,67 & 44,64 \\
\hline Lâmina deficiente & 29,17 & 20,83 & 25,00 & 16,67 & 16,67 & 20,83 & 12,50 & 20,24 \\
\hline Lâmina crítica & 12,50 & 16,67 & 16,67 & 45,83 & 54,17 & 54,17 & 45,83 & 35,12 \\
\hline \multirow[t]{2}{*}{ Total (\%) } & 100 & 100 & 100 & 100 & 100 & 100 & 100 & 100 \\
\hline & \multicolumn{8}{|c|}{ Semeadura de 10 de novembro } \\
\hline Lâmina ótima & 75,00 & 75,00 & 45,83 & 20,83 & 29,17 & 41,67 & 50,00 & 48,21 \\
\hline Lâmina deficiente & 12,50 & 12,50 & 41,67 & 33,33 & 25,00 & 12,50 & 12,50 & 21,43 \\
\hline Lâmina crítica & 12,50 & 12,50 & 12,50 & 45,83 & 45,83 & 45,83 & 37,50 & 30,36 \\
\hline Total $(\%)$ & 100 & 100 & 100 & 100 & 100 & 100 & 100 & 100 \\
\hline
\end{tabular}

* VE-V6 - Emergência à sexta folha; V7 - Sétima folha; V10 - Décima folha; VT - Pendoamento; A-F(R1) - Antese-Florescimento (fecundação); R2 - Grão leitoso; R3 - Grão pastosoLâmina ótima:1) Estádio VE-V6 = até $18 \mathrm{~mm} ; 2$ ) Demais estádios = até $32 \mathrm{~mm}$

Lâmina deficiente: 1) Estádio VE-V6 = entre 18 e $27 \mathrm{~mm}$; 2) Demais estádios = entre 32 e $48 \mathrm{~mm}$ 
estádios de desenvolvimento da cultura, de acordo com as diferentes datas de semeadura. Para este processo foram considerados os limites inerentes aos conceitos de lâmina ótima, lâmina deficiente e lâmina crítica.

Nos estádios fenológicos iniciais de VE a V10-VT (Figura 1A, B e C) os valores da ETmc acumulada se apresentam crescentes dentro do intervalo de lâmina crítica variando entre aproximados 40 a $100 \mathrm{~mm}$, respectivamente; contudo, a partir do estádio VT ocorreram valores extremos de redução do armazenamento de água no solo, como nos anos de 1984, 1985, 1988, 1990, 2004 e 2005, anos em que se estimou a ocorrência de ETmc acumulada extrema de $190 \mathrm{~mm}$, com maior frequência no estádio R3 (Figura 1D, E, F e G).

Petry et al. (2007) observaram que, em anos secos como esses, a restrição hídrica ocasiona impactos expressivos sobre as plantas de milho reduzindo seu desenvolvimento e produtividade, em lavouras não irrigadas. Para Caramori (2003) a observação do zoneamento agrícola ao se eleger a data para semeadura, pode colaborar para se reduzir os riscos de perda de produção, diminuindo a exposição da cultura aos períodos mais prováveis de baixa disponibilidade hídrica às plantas. A probabilidade de ocorrência dos diferentes valores de ETmc acumulada nos limites considerados, é apresentada na Tabela 8.

Observa-se, independente da data de semeadura, que com o avanço dos estádios fenológicos para a fase reprodutiva a incidência ETmc acumulada tende a aumentar no intervalo da lâmina crítica e a diminuir no intervalo da lâmina ótima, sendo o maior índice $(48,21 \%)$ verificado para semeaduras no final do período recomendado.

A classificação da intensidade da deficiência considerandose a ocorrência da ETmc acumulada nos subintervalos da lâmina deficiente para os diferentes estádios fenológicos e datas de semeadura, é apresentada na Tabela 9; o valor zero corresponde à lâmina ótima e a ocorrência de incidência de ETmc acumulada no intervalo da lâmina crítica é contabilizada no valor máximo do intervalo 76 a $100 \%$.

Com relação à época de semeadura verifica-se que as datas mais tardias, 31 de outubro e 10 de novembro, ocasionam as maiores probabilidades de disponibilidade hídrica ótima $(44,64$ e $48,21 \%$ ) e as menores probabilidades de deficiência hídrica na classe de 76 a 100\% (43,45 e 41,07\%), respectivamente. Para esta data de semeadura a probabilidade de deficiência hídrica no estádio A-F(R1) com intensidade na classe 76 a 100\%, é menor, embora o índice de 58,3\% seja ainda elevado.

Considerando-se a média geral verifica-se que, independente da data de semeadura, a maior concentração de ETmc acumulada ocorre na classe 76 a $100 \%$; observa-se, além disto, que o estádio fenológico A-F(R1) apresenta $65,28 \%$ de probabilidade de ocorrência de déficit hídrico com severidade entre 76 e $100 \%$ e, junto com o estádio VT, apresentam as mais baixas probabilidades de fugir completamente da deficiência hídrica (valor zero abaixo de $30 \%$ ).

Deve-se destacar a relevância deste resultado visto que Bergamaschi et al. (2004) observaram que A-F(R1) é um período curto e bem definido durante o qual a cultura apresenta sensibilidade crítica à deficiência hídrica. Neste sentido, Carlesso et al. (2000) salientam que a cultura apresenta relativa tolerância à falta de água durante o desenvolvimento vegetativo
Tabela 9. Classificação da intensidade de ocorrência de deficiência hídrica nos estádios fenológicos da cultura do milho em diferentes datas de semeadura, com base em dados climáticos do período 1984 - 2007

\begin{tabular}{|c|c|c|c|c|c|}
\hline \multirow{2}{*}{$\begin{array}{l}\text { Estádio } \\
\text { fenológico }\end{array}$} & \multicolumn{5}{|c|}{ Intensidade da deficiência hídrica (\%) } \\
\hline & Zero & 1 a 25 & 26 a 50 & 51 a 75 & 76 a 100 \\
\hline & \multicolumn{5}{|c|}{ Semeadura de 21 de setembro } \\
\hline VE-V6 & 79,17 & 4,17 & 4,17 & 4,17 & 8,33 \\
\hline V7-V10 & 75,00 & 8,33 & 12,50 & 0,00 & 4,17 \\
\hline V10-VT & 25,00 & 8,33 & 16,67 & 8,33 & 41,67 \\
\hline VT & 25,00 & 4,17 & 4,17 & 0,00 & 66,67 \\
\hline$A-F(R 1)$ & 29,17 & 0,00 & 0,00 & 0,00 & 70,83 \\
\hline $\mathrm{R} 2$ & 33,33 & 4,17 & 4,17 & 0,00 & 58,33 \\
\hline R3 & 29,17 & 0,00 & 4,17 & 0,00 & 66,67 \\
\hline \multirow[t]{2}{*}{$\%$} & 42,26 & 4,17 & 6,55 & 1,79 & 45,24 \\
\hline & \multicolumn{5}{|c|}{ Semeadura de 1 de outubro } \\
\hline VE-V6 & 70,83 & 20,83 & 8,33 & 0,00 & 0,00 \\
\hline V7-V10 & 62,50 & 8,33 & 4,17 & 4,17 & 20,83 \\
\hline V10-VT & 25,00 & 4,17 & 8,33 & 4,17 & 58,33 \\
\hline $\mathrm{VT}$ & 25,00 & 4,17 & 0,00 & 4,17 & 66,67 \\
\hline$A-F(R 1)$ & 33,33 & 0,00 & 4,17 & 0,00 & 62,50 \\
\hline $\mathrm{R} 2$ & 33,33 & 4,17 & 4,17 & 0,00 & 58,33 \\
\hline R3 & 29,17 & 8,33 & 8,33 & 0,00 & 54,17 \\
\hline \multirow[t]{2}{*}{$\%$} & 39,88 & 7,14 & 5,36 & 1,79 & 45,83 \\
\hline & \multicolumn{5}{|c|}{ Semeadura de 11 de outubro } \\
\hline VE-V6 & 75,00 & 4,17 & 4,17 & 0,00 & 16,67 \\
\hline V7-V10 & 58,33 & 12,50 & 4,17 & 0,00 & 25,00 \\
\hline V10-VT & 37,50 & 0,00 & 4,17 & 4,17 & 54,17 \\
\hline VT & 29,17 & 8,33 & 8,33 & 0,00 & 54,17 \\
\hline$A-F(R 1)$ & 33,33 & 0,00 & 0,00 & 0,00 & 66,67 \\
\hline $\mathrm{R} 2$ & 29,17 & 0,00 & 12,50 & 0,00 & 58,33 \\
\hline R3 & 29,17 & 4,17 & 4,17 & 4,17 & 58,33 \\
\hline \multirow[t]{2}{*}{$\%$} & 41,67 & 4,17 & 5,36 & 1,19 & 47,62 \\
\hline & \multicolumn{5}{|c|}{ Semeadura de 21 de outubro } \\
\hline VE-V6 & 66,67 & 8,33 & 4,17 & 4,17 & 16,67 \\
\hline V7-V10 & 54,17 & 0,00 & 8,33 & 0,00 & 37,50 \\
\hline V10-VT & 41,67 & 8,33 & 0,00 & 4,17 & 45,83 \\
\hline $\mathrm{VT}$ & 41,67 & 0,00 & 0,00 & 4,17 & 54,17 \\
\hline$A-F(R 1)$ & 25,00 & 8,33 & 0,00 & 0,00 & 66,67 \\
\hline $\mathrm{R} 2$ & 20,83 & 12,50 & 8,33 & 0,00 & 58,33 \\
\hline R3 & 16,67 & 0,00 & 20,83 & 4,17 & 58,33 \\
\hline \multirow[t]{2}{*}{$\%$} & 38,10 & 5,36 & 5,95 & 2,38 & 48,21 \\
\hline & \multicolumn{5}{|c|}{ Semeadura de 31 de outubro } \\
\hline VE-V6 & 58,33 & 4,17 & 0,00 & 0,00 & 37,50 \\
\hline V7-V10 & 62,50 & 8,33 & 4,17 & 0,00 & 25,00 \\
\hline V10-VT & 58,33 & 4,17 & 8,33 & 0,00 & 29,17 \\
\hline VT & 37,50 & 0,00 & 0,00 & 8,33 & 54,17 \\
\hline$A-F(R 1)$ & 29,17 & 0,00 & 0,00 & 4,17 & 66,67 \\
\hline $\mathrm{R} 2$ & 25,00 & 12,50 & 12,50 & 4,17 & 45,83 \\
\hline R3 & 41,67 & 4,17 & 4,17 & 4,17 & 45,83 \\
\hline \multirow[t]{2}{*}{$\%$} & 44,64 & 4,76 & 4,17 & 2,98 & 43,45 \\
\hline & \multicolumn{5}{|c|}{ Semeadura de 10 de novembro } \\
\hline VE-V6 & 75,00 & 0,00 & 0,00 & 8,33 & 16,67 \\
\hline V7-V10 & 75,00 & 12,50 & 0,00 & 0,00 & 12,50 \\
\hline V10-VT & 45,83 & 0,00 & 4,17 & 4,17 & 45,83 \\
\hline VT & 20,83 & 8,33 & 4,17 & 4,17 & 62,50 \\
\hline$A-F(R 1)$ & 29,17 & 4,17 & 4,17 & 4,17 & 58,33 \\
\hline $\mathrm{R} 2$ & 41,67 & 4,17 & 4,17 & 0,00 & 50,00 \\
\hline R3 & 50,00 & 8,33 & 0,00 & 0,00 & 41,67 \\
\hline$\%$ & 48,21 & 5,36 & 2,38 & 2,98 & 41,07 \\
\hline & & édia gera & ra as fas & enológica & \\
\hline VE-V6 & 70,83 & 6,94 & 3,47 & 2,78 & 15,97 \\
\hline V7-V10 & 64,58 & 8,33 & 5,56 & 0,69 & 20,83 \\
\hline V10-VT & 38,89 & 4,17 & 6,94 & 4,17 & 45,83 \\
\hline VT & 29,86 & 4,17 & 2,78 & 3,47 & 59,72 \\
\hline$A-F(R 1)$ & 29,86 & 2,08 & 1,39 & 1,39 & 65,28 \\
\hline $\mathrm{R} 2$ & 30,56 & 6,25 & 7,64 & 0,69 & 54,86 \\
\hline R3 & 32,64 & 4,17 & 6,94 & 2,08 & 54,17 \\
\hline & & ias geral & ra as data & e semead & \\
\hline VE-V6 & 42,46 & 5,16 & 4,96 & 2,18 & 45,24 \\
\hline
\end{tabular}


porém demonstra extrema sensibilidade, com decréscimo no rendimento de grãos se o déficit hídrico ocorrer na antese e florescimento.

Na Tabela 10 são apresentadas as estimativas de produtividade da cultura para as diferentes datas de semeadura a partir do teto de produção regional de $14.000 \mathrm{~kg} \mathrm{ha}^{-1}$. Os dados médios foram obtidos a partir dos valores anuais de ETmc calculados para cada estádio fenológico nas distintas datas de semeadura (Figura 1) considerando-se os efeitos de redução na produção de grãos pela deficiência hídrica, conforme a Tabela 4 .

Tabela 10. Produtividade da cultura do milho estimada em função da probabilidade de ocorrência de deficiência hídrica nos estádios fenológicos da cultura do milho em diferentes datas de semeadura, com base em dados climáticos do período 1984 - 2007

\begin{tabular}{lrrrrrr}
\hline \multirow{2}{*}{$\begin{array}{c}\text { Estádio } \\
\text { fenológico }\end{array}$} & \multicolumn{5}{c}{ Data de semeadura } \\
\cline { 2 - 7 } & 21-set & 1-out & 11-out & 21-out & 31-out & 10-Nov \\
\cline { 2 - 7 } VE-V6 & 0,63 & 0,37 & 0,93 & 1,13 & 1,92 & 1,07 \\
V7-V10 & 0,51 & 1,29 & 1,41 & 1,99 & 1,38 & 0,70 \\
V10-VT & 5,44 & 6,41 & 5,73 & 4,69 & 3,28 & 4,90 \\
VT & 10,23 & 10,39 & 8,75 & 8,56 & 9,02 & 10,18 \\
A-F(R1) & 24,79 & 22,42 & 21,78 & 23,33 & 23,88 & 21,93 \\
R2 & 5,64 & 6,07 & 6,33 & 6,35 & 5,55 & 9,19 \\
R3 & 3,41 & 3,15 & 3,19 & 3,42 & 2,53 & 2,07 \\
\hline \% Redução & 50,70 & 50,10 & 48,20 & 49,48 & 47,55 & 50,03 \\
Produção kg ha-1 & 6902 a & 6986 a & 7252 a & 7072 a & 7341 a & 6995 a \\
\hline
\end{tabular}

* VE-V6 - Emergência à sexta folha; V7-V10 - Sétima à décima folha; V10-VT - Décima folha ao pendoamento; VT - Pendoamento; A-F(R1) - Antese-Florescimento (fecundação); R2 - Grão leitoso; R3 - Grão pastoso

DMS - $2348 \mathrm{~kg} \mathrm{ha}^{-1}$; CV\% - 39,24; média - $7091 \mathrm{~kg} \mathrm{ha}^{-1}$

Na linha, médias seguidas da mesma letra não diferem estatisticamente entre si pelo Teste de Tukey $(p<0,05)$

As estimativas das produtividades para as diferentes datas de semeadura considerando-se o período de 1984 a 2007 são apresentadas na Figura 2. O intervalo de confiança em torno da média foi estabelecido a partir da diferença mínima significativa para a comparação de médias (DMS) de $2348 \mathrm{~kg} \mathrm{ha}^{-1}$, conforme apresentado na Tabela 10; caso em que a obtenção de produti-

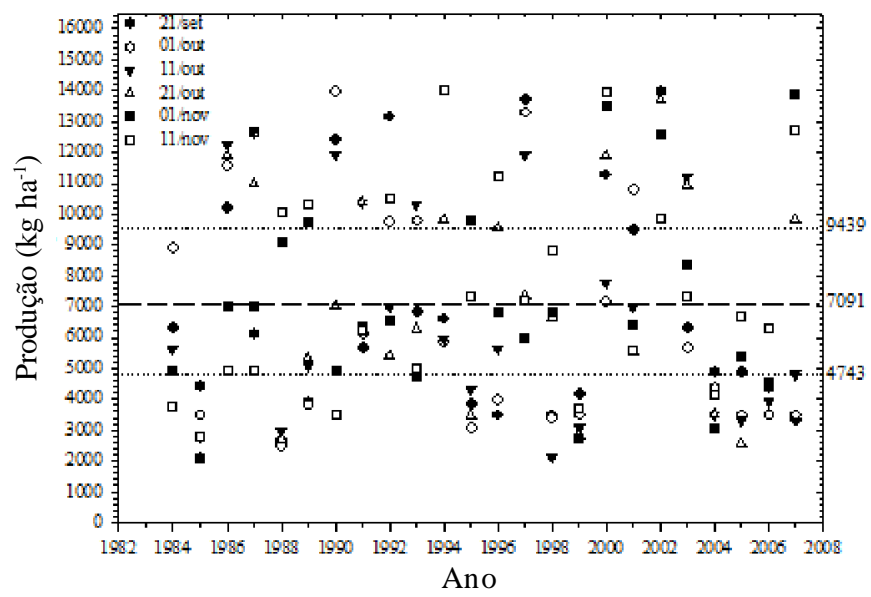

Figura 2. Comportamento da produtividade estimada (kg ha'-1) em função da variação da disponibilidade hídrica no ciclo da cultura do milho, em diferentes datas de semeadura no período 1984-2007 vidade no intervalo da média pode significar qualquer valor entre 4743 e $9439 \mathrm{~kg} \mathrm{ha}^{-1}$. Segundo Letey (1985) estimativas de produção com grandes variabilidades, como as em discussão, são indesejáveis, pois representam riscos indicando baixa sustentabilidade da atividade agrícola.

Se forem associados os dados de produtividade da Figura 2 com as avaliações em relação ao comportamento da ETmc acumulada apresentadas na Figura 1, observa-se que os anos nos quais existiram valores extremos de redução do armazenamento de água no solo como em 1984, 1985, 1988, 1990, 2004 e 2005, são os que se destacam com estimativa de produção abaixo da média.

Na Figura 3 é apresentada a análise do comportamento da produção em relação ao intervalo de confiança em torno da média, com a adição de linhas de tendência. Constata-se que a semeadura no final do período recomendado diminui a probabilidade de obtenção de produtividades abaixo da média. Esta constatação é fundamental pois, devido à grande amplitude do referido intervalo, valores abaixo da média significam redução de no mínimo de $66 \%$ na produtividade em relação ao teto de produção estabelecido.

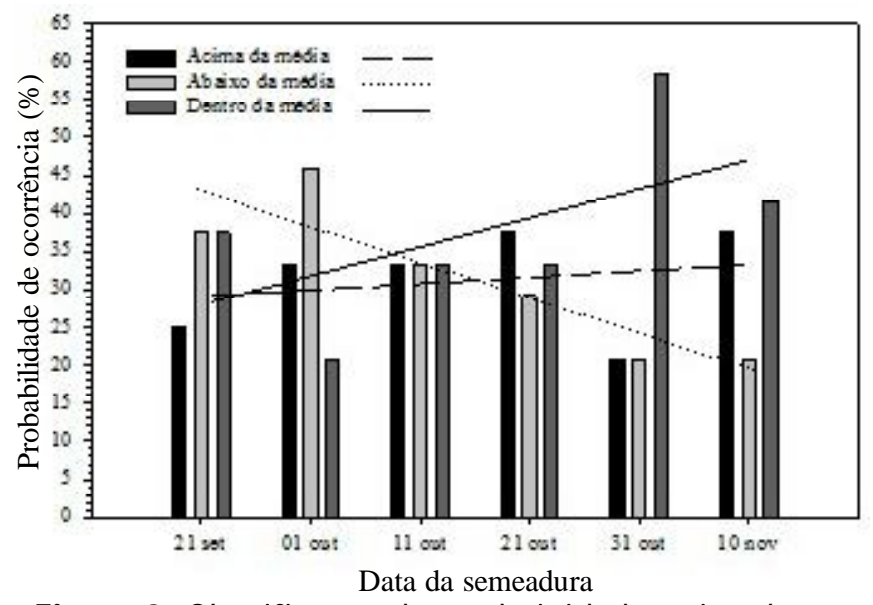

Figura 3. Classificação da produtividade estimada em função da disponibilidade hídrica no ciclo da cultura do milho em diferentes datas de semeadura

Quando a semeadura é realizada em 21 de setembro estimamse $37,5 \%$ de probabilidade de que a produtividade esteja dentro ou abaixo da média e apenas $25 \%$ acima; a semeadura em 1 de outubro apresenta grande oscilação da produção estimada, com $45,8 \%$ de probabilidade de que esta esteja abaixo e 33,3\% acima do intervalo da média.

Tal comportamento variável é também observado para a semeadura em 11 de outubro, época em que as probabilidades de ocorrência de eventos em torno do intervalo da média são similares $(33,3 \%)$; consequentemente, a soma das probabilidades de a produção estar dentro ou abaixo da média, é de $66 \%$; nesta perspectiva a semeadura em 21 de outubro apresenta melhores resultados, com $37,5 \%$ de probabilidade de obtenção de produção superior e $29 \%$ inferior ao intervalo da média.

Em relação à estabilidade de produção a data de semeadura em 31 de outubro apresentou a probabilidade de produção dentro do intervalo da média $(58,3 \%)$, resultado que seria 
vantajoso caso a amplitude deste intervalo fosse menor; contudo, é interessante, devido ao menor risco de se produzir abaixo da média.

A semeadura em 10 de novembro apresenta as melhores estimativas em relação à estabilidade de produção, com a maior probabilidade (37\%) de que a produção obtida esteja acima do intervalo da média e associada com uma das menores $(20,8 \%)$ de se produzir abaixo do intervalo da média. Para Claassen \& Shaw (1970) dentre os fatores climáticos a distribuição das precipitações é a que está mais frequentemente associada à redução da capacidade produtiva do milho em dada região; em contrapartida, a produtividade média pode não representar, economicamente, bons retornos aos investimentos de cultivo.

Com esses resultados e observando o comportamento das linhas de tendência da Figura 3, verifica-se que em Guarapuava, $\mathrm{PR}$, é mais apropriada a semeadura do milho em datas mais tardias dentro do calendário recomendado pelo zoneamento agrícola; neste sentido, os dados apresentados na Tabela 9 evidenciam que as datas de semeadura mais tardias, em 31 de outubro e 10 de novembro, ocasionam as menores probabilidades de ocorrência de déficit hídrico e que a severidade da deficiência hídrica possa ser extrema, sendo que na última data as probabilidades de deficiência hídrica no estádio A-F(R1) são menores em relação às demais.

Em concordância com tais resultados e considerando o manejo da cultura do milho, Faria et al. (2000) descrevem que o conhecimento da lâmina total de água consumida pela cultura em cada um dos vários períodos de crescimento, permite ajustar as datas da semeadura de forma que as fases de crescimento mais críticas coincidam com os períodos de menor probabilidade de deficiência hídrica; neste sentido, Nied et al. (2005) verificaram, em pesquisa na região central do Rio Grande do Sul, que semeaduras realizadas em outubro apresentam, em média, maior probabilidade de ocorrência de deficiências hídricas uma vez que o subperíodo compreendido entre a antese e o início de enchimento do grão culmina com a menor ocorrência de chuvas, nesta região.

\section{ConclusõES}

1. A cultura do milho é afetada pela distribuição da disponibilidade de água ao longo do ciclo fenológico e a probabilidade média de redução de produção por deficiência hídrica é de aproximadamente $50 \%$.

2. A probabilidade estimada de ocorrência de deficiência hídrica nos diferentes estádios fenológicos da cultura é afetada pela época de semeadura enquanto o estádio fenológico com maior índice de probabilidade de submissão ao déficit hídrico, é A-F(R1) (antese fecundação).

3. Semeaduras mais tardias no período recomendado ocasionam menor probabilidade de produção de grãos abaixo do intervalo da média reduzindo a oscilação de produção, ao longo dos anos.

4. Adata 10 de novembroé a mais indicada para a semeadura do milho por ocasionar as maiores probabilidades de obtenção de produção de grãos dentro ou acima do intervalo da média, associados com os menores índices de ocorrência de deficiência hídrica no estádio A-F(R1) (antese fecundação).

\section{LITERATURA CITADA}

Allen, R. G.; Pereira, L. S.; Raes, D.; Smith, M. Crop evapotranspiration. Rome: FAO, 1998. 328p. Irrigation and Drainage Paper, 56

Bergamaschi, H.; Dalmago, G.; Bergonci, J. I.; Bianchi, C. A. M.; Müller, A. G.; Comiran, F.; Heckler, B. M. Distribuição hídrica no período crítico do milho e produção de grãos. Pesquisa Agropecuária Brasileira, v.39, p.831-839, 2004.

Bergamaschi, H.; Dalmago, G A.; Comiran, F.; Bergonci, J. I.; Müller, A. G.; França, S.; Santos, A. O.; Radin, B.; Bianchi, C. A. M.; Pereira, P. G. Deficit hídrico e produtividade na cultura do milho. Pesquisa Agropecuária Brasileira, v.41, p.243-249. 2006.

Camp, C. R.; Campbell, R. B. Scheduling irrigation for corn and soybean in the southeast coastal plain. American Society of Agriculture Engineers, v.31, p.513-518, 1998.

Caramori, P. H. Zoneamento agrícola no estado do Paraná. Londrina: Instituto Agronômico do Paraná, 2003. 76p.

Cargnelutti Filho, A.; Matzenauer, R.; Trindade, J. K. da. Ajustes de funções de distribuição de probabilidade à radiação solar global no estado do Rio Grande do Sul. Pesquisa Agropecuária Brasileira, v.39, p.1157-1166, 2004.

Carlesso, R.; Peiter, M. X.; Christofari, C. P.; Petry, M. T. Manejo da irrigação do milho a partir da evapotranspiração máxima da cultura. Engenharia Agrícola, v.20, p.15-23, 2000.

Castellví, F.; Mormeneo, I.; Perez, P. J. Generation of daily amounts of precipitation from standard climatic data: A case study for Argentina. Journal of Hydrology, v.289, p.286302, 2004.

Claassen, M. M.; Shaw, R. H. Water deficit effects on corn. II. Grain components. Agronomy Journal, v.62, p.652-655, 1970.

Constantin, J.; Oliveira Júnior, R. S.; Cavalieri, S. D.; Arantes, J. G. Z.; Alonso, D. G.; Roso, A. C.; Costa, J. M. Interação entre sistemas de manejo e de controle de plantas daninhas em pós-emergência afetando o desenvolvimento e a produtividade do milho. Planta Daninha, v.25, p.513-520, 2007.

Costa, J. R. da; Pinho, J. L. N. de; Parry, M. Produção de matéria seca de cultivares de milho sob diferentes níveis de estresse hídrico. Revista Brasileira de Engenharia Agrícola e Ambiental, v.12, p.443-450, 2008.

Dallacort, R.; Freitas, P. S. L.; Faria, R. T.; Gonçalves, A. C. A.; Rezende, R.; Bertonha, A. Utilização do modelo Cropgrosoybean na determinação de melhores épocas de semeadura da cultura da soja, na região de Palotina, Paraná. Acta Scientiarum Agronomy, v.28, p.583-589, 2006.

Doorenbos, J.; Kassam, A. H. Yield response to water. Rome, FAO, 1979. 172p. FAO: Irrigation and Drainage Paper, 33

EMBRAPA - Empresa Brasileira de Pesquisa Agropecuária Embrapa. Sistema brasileiro de classificação de solos. 2 ed. Rio de Janeiro: Embrapa Solos, 2006. 306p.

Espinoza, W. Extração de água pelo milho em latossolo da região dos cerrados. Pesquisa Agropecuária Brasileira, v.15, p.69-78, 1980. 
Fancelli, A. L.; Dourado Neto, D. Fenologia do milho. In: Fancelli, A. L.; Dourado Neto, D. (Coord.). Tecnologia da produção de milho. Piracicaba: Publique, 1997. p.131-140.

Faria, R. E. de; Soares, A. L.; Sediyama, G. C.; Ribeiro, C. A. Demanda suplementar de irrigação para a cultura do milho no Estado de Minas Gerais. Revista Brasileira de Engenharia Agrícola e Ambiental, v.4, p.46-50, 2000.

Fiorin, T. T.; Spohr, R. B.; Carlesso, R.; Michelon, C. J.; Santa, C. D.; David, G. de Produção de silagem de milho sobre camalhões em solos de várzea. Revista Pesquisa Aplicada \& Agrotecnologia, v.2, p.148-153, 2009.

Forsthofer, E. L.; Silva, P. R. F. da; Argenta, G.; Strieder, M. L.; Suhre, E.; Rambo, L. Desenvolvimento fenológico e agronômico de três híbridos de milho em três épocas de semeadura. Ciência Rural, v.34, p.1341-1348, 2004.

Gadioli, J. L.; Dourado Neto, D.; García, A. G.; Basanta, M. V. Temperatura do ar, rendimento de grãos de milho e caracterização fenológica associada à soma calórica. Scientia Agrícola, v.57, p.377-383, 2000.

Klar, A. E.; Jadoski, S. O.; Lima, J. P. P. Peroxidase activity as an indicator of water stress in sweet pepper plantas. Irriga, v.11, p.441-447, 2006.

Letey, J. Irrigation uniformity as related to optimum crop production - Additional research is needed. Irrigation Science, v.6, p.253-263, 1985.

Monteith, J. L.; Elston, J. Climatic constraints on crop production, In: Fowden, L.; Mansfield, T.; Stoddart, J. (Eds). Plant adaptation to environmental stress. London: Chapman e Hall, 1996. p.3-18.
Nied, A. H.; Heldwein, A. B.; Estefanel, V.; Silva, J. C.; Alberto, C. M. Épocas de semeadura de milho com menor risco de ocorrência de deficiência hídrica no município de Santa Maria, RS, Brasil. Ciência Rural, v.35, p.995-1002, 2005.

Pereira, A. R. Simplificado o balanço hídrico de ThornthwaiteMather. Bragantia, v.64, p.311-313, 2005.

Petry, M. T.; Zimmermann, F. L.; Carlesso, R.; Michelon, C. J.; Khunz, J. H. Disponibilidade de água do solo ao milho cultivado sob sistemas de semeadura direta e preparo convencional. Revista Brasileira de Ciência do Solo, v.31, p.531-539, 2007.

Ritchie, S. W.; Hanway, J. J.; Benson, G. O. How a corn plant develops. Ames, Iowa State University of Science and Technology, 1993. Ames, Iowa, 1993. 21p. Special Report No. 48.

SEAB-DERAL - Secretaria da Agricultura e do AbastecimentoDepartamento de Economia Rural. Área e produção agrícola no estado do Paraná e comparativo com o Brasil. Curitiba, 2007.66p.

Tacker, P.; Vories, E.; Huitink, G. Drainage and irrigation. In: Corn production handbook. Fayetteville: University Arkansas, Division Agriculture, 2003. p.13-22.

Villa-Nova, N. A.; Pereira, A. B. Ajuste do método de PriestleyTaylor às condições climáticas locais. Engenharia Agrícola, v.26, p.395-405, 2006. 